\title{
PERANCANGAN SISTEM INFORMASI PENERIMAAN SISWA BARU PADA MTS. AL - FURQON BANJARMASIN
}

\author{
${ }^{(1)}$ Muthia Farida, ${ }^{(2)}$ Dian Agustini \\ (1)(2)Teknik Informatika, Fakultas Teknologi Informasi, Universitas Islam Kalimantan \\ MAB \\ Jl. Adhiyaksa No. 2 Kayu Tangi, Banjarmasin \\ Email : muthiafarida59@gmail.com,dian.da989@gmail.com
}

\begin{abstract}
Abstrak
Penelitian ini bertujuan untuk membuat sebuah sistem informasi penerimaan siswa baru agar mempermudah pihak sekolah dalam proses pengolahan data calon siswa lebih cepat dan akurat dengan tahapan metode penelitian : 1 . Tahap pengumpulan data yaitu : a) wawancara dengan berkomunikasi secara langsung dengan bagian kepala sekolah, guru serta tata usaha, b) observasi atau pengamatan langsung, c) studi literatur dengan cara mereview jurnal-jurnal ilmiah, buku atau berbagai sumber yan terkait dengan penelitian yang akan dibuat. 2. Analisi kebutuhan sistem. 3. Tahap desain sistem yang menetukan proses dan data yang diperlukan oleh sistem baru. 4. Implementasi sistem serta pengujian sistem menggunakan metode black box dengan keberhasilan pengujian sistem yang dibuat.
\end{abstract}

Kata Kunci : Blackbox, Data Siswa, Sistem Informasi

\begin{abstract}
This study aims to create a new student admission information system to make it easier for schools in prospective student data processing faster and more accurate with the stages of research methods: 1. Data collection phase, namely: a) interviews by communicating directly with the headmaster, teacher and administration, b) observation or direct observation, c) study of literature by reviewing scientific journals, books or various sources related to the research that will be made. 2. Analysis of system requirements. 3 . The stage of system design determines the processes and data needed by the new system. 4 . Implementation of the system and system testing using the black box method with the success of the system testing made.
\end{abstract}

Keywords : Blackbox, Student Data, Information System

\section{PENDAHULUAN}

Dewasa ini perkembangan teknologi begitu pesat. Hampir seluruh aspek kehidupan memiliki keterkaitan dengan teknologi informasi. Seperti halnya dalam dunia pendidikan, banyak sekolah telah menggunakan sistem informasi dalam proses kegiatan operasionalnya sehari-hari. Sejalan dengan itu aktivitas-aktivitas yang selama ini dijalankan secara manual sudah mulai memanfaatkan teknologi informasi guna membantu dalam pemrosesan data yang kompleks sehingga dapat menghasilkan informasi 
yang cepat, tepat, akurat dan up to date. Pengambilan sebuah keputusan merupakan proses pemilihan diantara berbagai macam alternative yang bertujuan untuk memenuhi satu atau beberapa sasaran. Salah satu contoh pengambilan keputusan dalam dunia pendidikan adalah dalam proses penetapan calon siswa baru disekolah. Pengambilan keputusan untuk meluluskan calon siswa untuk menjadi siswa baru disekolah tersebut. Salah satunya pada Sekolah MTs Al - Furqon Banjarmasin. Seiring dengan perkembangan teknologi, maka sekolah MTs Al - Furqon memerlukan sebuah alat bantu yang mempermudah pihak sekolah dalam proses pengambilan keputusaan saat proses penerimaan siswa baru berlangsung

\section{METODE PENELITIAN}

Metode Penelitian yang dipakai menggunakan Metode Eksperimen dengan Tahapan yang pertama adalah Tahap Pengumpulan Data. Beberapa tahapan dalam pengumpulan data yaitu yang pertama adalah Wawancara yaitu Teknik Pengumpulan data dengan cara berkomunikasi secara langsung dengan kepala sekolah, guru serta tata usaha. Yang kedua adalah Observasi (Pengamatan Langusng) yaitu Teknik pengumpulan data yang dilakukan dengan mengadakan pengamatan secara langsung terhadap sistem yang ada pada MTS Al - Furqon Banjarmasin Dan yang ketiga adalah Studi Literatur yaitu teknik pengumpulan data dengan cara mereview jurnal-jurnal ilmiah, buku dan berbagai sumber refrensi yang terkait tentang penelitian yang akan dibuat.

Selanjutnya adalah Tahap Analisis Kebutuhan Sistem yaitu merupakan kegiatan penguraian suatu sistem informasi yang utuh ke dalam beberapa bagian yang menuntut kita untuk melakukan identifikasi dan evaluasi terhadap permasalahan yang ada dan menentukan kebutuhan sistem dalam rangka mengusulkan perbaikan sistem. Selanjutnya Tahap Desain Sistem merupakan tahap setelah analisa sistem yang menentukan proses dan data yang diperlukan oleh sistem baru dengan tujuan untuk memenuhi kebutuhan kepada para pemakai, serta memberikan gambaran yang jelas dan rancang bangun yang lengkap kepada pemrogram komputer dan ahli teknik lain yang terlibat. Tahapan selanjutnya adalah impelemntasi dari sistem yang dibuat serta pengujian dari sistem yang dibuat.

\section{HASIL DAN PEMBAHASAN}

Implementasi Sistem yang pertama adalah gambaran dari aplikasi atau program yang telah dibuat.

1) Form Login untu masuk kedalam sistem

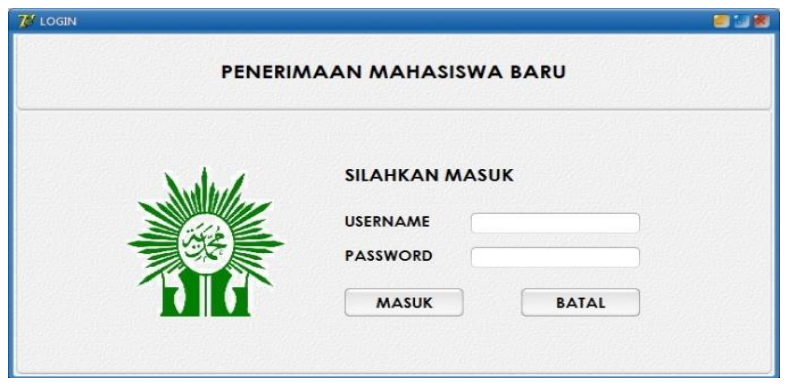

2) Form Menu Utama

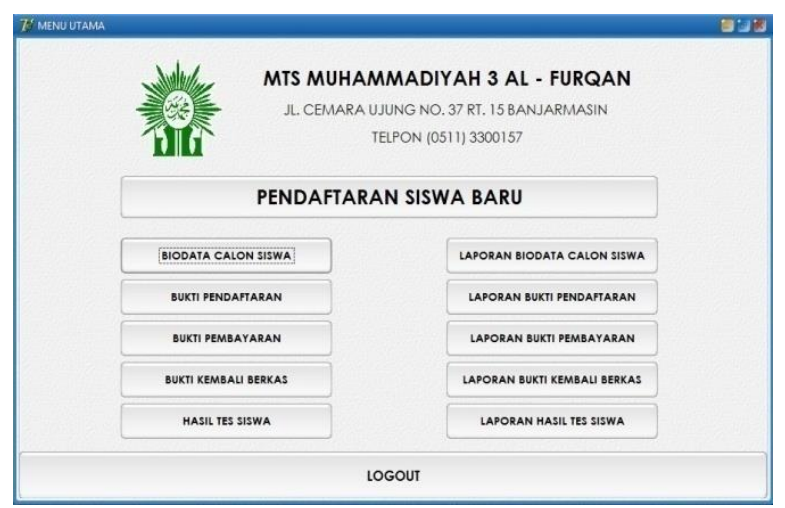


3) Form Biodata Siswa

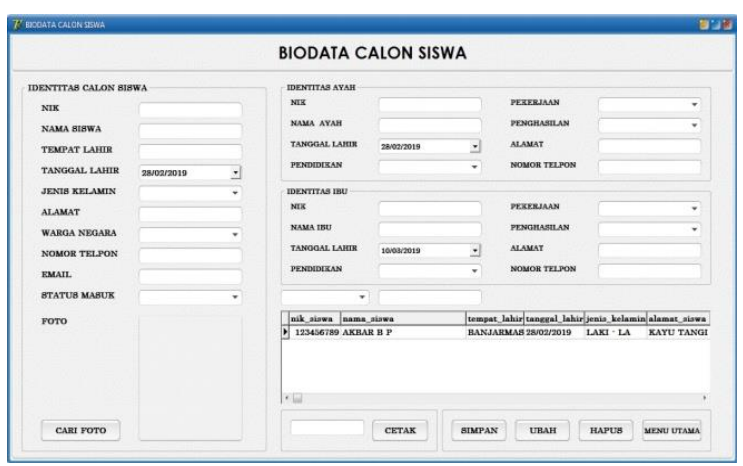

4) Form Bukti Pendaftaran Siswa Baru

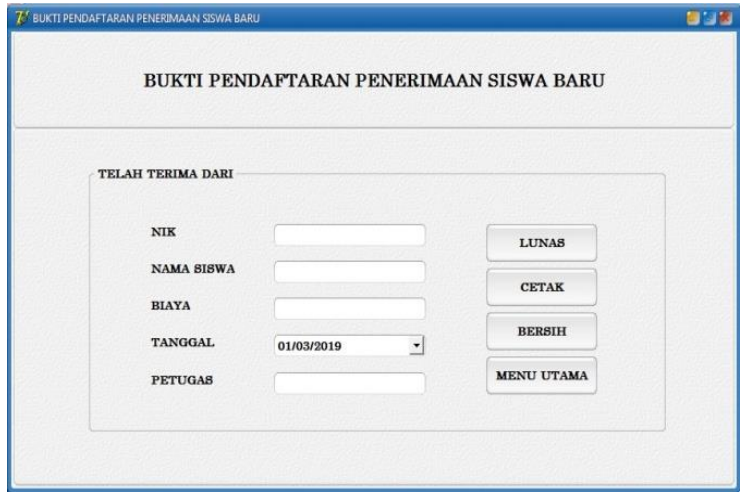

5) Form Bukti Kembali Berkas Siswa Baru

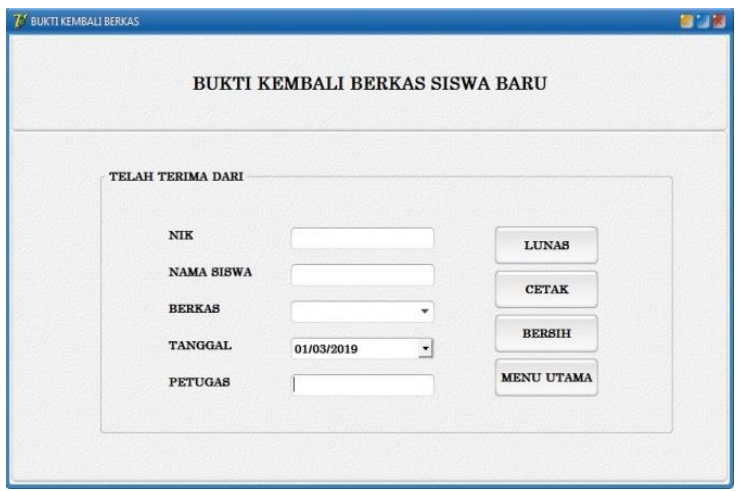

6) Form Hasil Tes Calon Siswa Baru

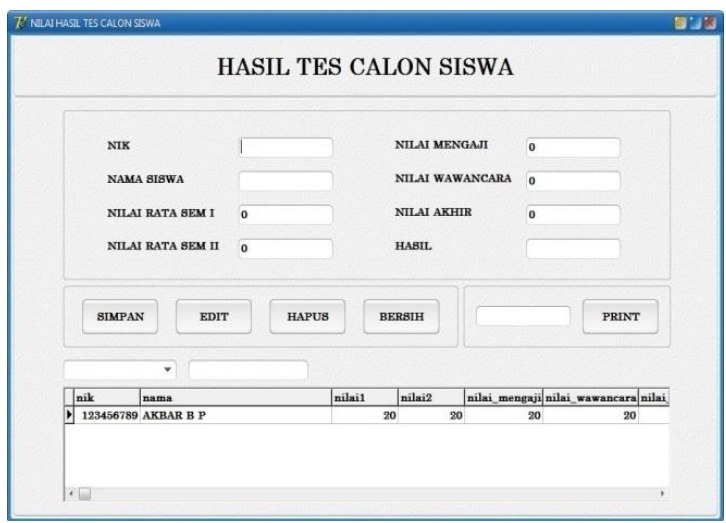

7) Form Bukti Pembayaran Registrasi Siswa Baru

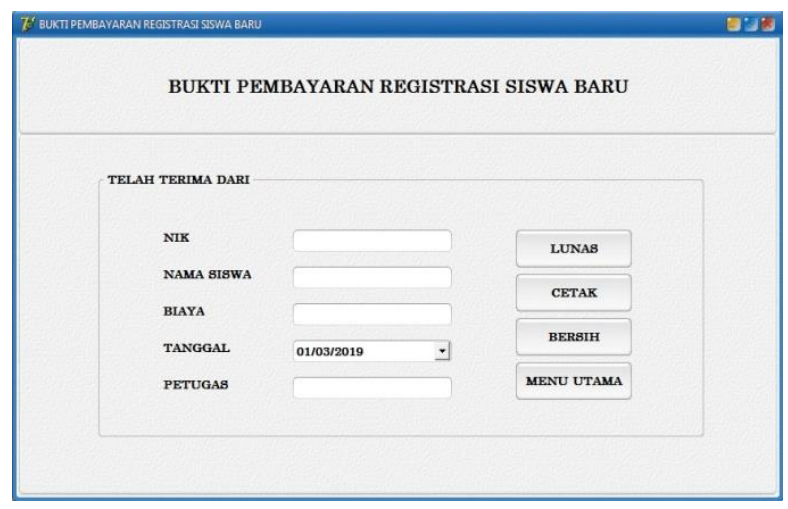

8) Form Cetak Biodata Calon Siswa Baru

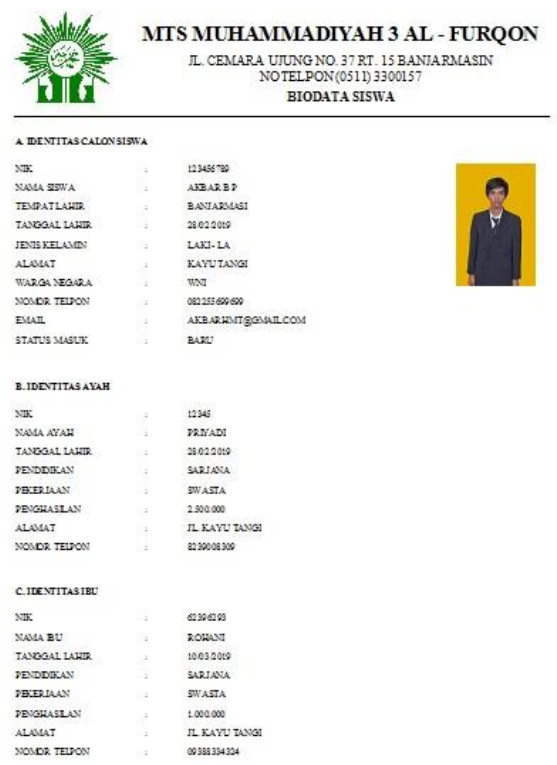

Yang selanjutnya dilakukan adalah Pengujian Sistem/Program Metode yang di gunakan dalam pengujian ini adalah menggunakan pengujian metode Black Box.

Tabel 1 Rencana Pengujian Sistem

\begin{tabular}{|l|l|l|}
\hline \multicolumn{1}{|c|}{ Item Uji } & $\begin{array}{c}\text { Detail } \\
\text { Pengujian }\end{array}$ & $\begin{array}{c}\text { Jenis } \\
\text { Pengujian }\end{array}$ \\
\hline Login & $\begin{array}{l}\text { Verivikasi } \\
\text { login staf }\end{array}$ & Black Box \\
\hline $\begin{array}{l}\text { Pengolahan } \\
\text { Data } \\
\text { Biodata }\end{array}$ & $\begin{array}{l}\text { Simpan, } \\
\text { Ubah, }\end{array}$ & Black Box \\
Hapus, & \\
\hline
\end{tabular}


p-ISSN 2502-4922,e-ISSN 2615-0867

\begin{tabular}{|l|l|l|}
\hline Calon & Cetak, & \\
Siswa & Keluar & \\
\hline Pengolahan & Simpan, & Black Box \\
Data Bukti & Cetak, & \\
Pendaftaran & Bersih, & \\
Siswa Baru & Keluar & \\
\hline Pengolahan & Simpan, & Black Box \\
Data Bukti & Cetak, & \\
Pembayaran & Bersih, & \\
Registrasi & Keluar & \\
Siswa Baru & & \\
\hline Pengolahan & Simpan, & Black Box \\
Data Bukti & Cetak, & \\
Kembali & Bersih, & \\
Berkas & Keluar & \\
Siswa Baru & & Black Box \\
\hline Pengolahan & Simpan, & \\
Data Hasil & Ubah, & \\
Tes Calon & Hapus, & \\
Siswa & Cetak, & \\
& Keluar & \\
\hline
\end{tabular}

\section{Kasus dan Hasil Pengujian}

Berdasarakan rencana pengujian yang telah disusun, maka dapat dilakukan pengujian sebagai berikut :

1. Login

Tabel 2 Pengujian Form Login

\begin{tabular}{|c|c|}
\hline \multicolumn{2}{|c|}{ Kasus dan Hasil Uji } \\
\hline Data Masukan & Username, password \\
\hline $\begin{array}{l}\text { Yang } \\
\text { diharapkan }\end{array}$ & $\begin{array}{l}\text { Data login } \\
\text { dimasukkan, isi } \\
\text { username da nisi } \\
\text { password lalu klik } \\
\text { tombol masuk } \\
\text { dilakukan proses } \\
\text { pengecekan data } \\
\text { login. Apabila data } \\
\text { login benar maka } \\
\text { user dapat } \\
\text { menjalankan system }\end{array}$ \\
\hline Pengamatan & $\begin{array}{l}\text { Dapat mengisi data } \\
\text { login sesuai dengan } \\
\text { yang diharapkan }\end{array}$ \\
\hline Kesimpulan & Sukses \\
\hline
\end{tabular}

2. Data Biodata Calon Siswa

Tabel 3 Pengujian Form Data Biodata

Calon Siswa

\begin{tabular}{|c|c|}
\hline \multicolumn{2}{|c|}{ Kasus dan Hasil Uji } \\
\hline \multicolumn{2}{|c|}{ Simpan Data } \\
\hline Data Masukan & $\begin{array}{l}\text { Mengisi data } \\
\text { Biodata Calon Siswa }\end{array}$ \\
\hline $\begin{array}{l}\text { Yang } \\
\text { diharapkan }\end{array}$ & $\begin{array}{l}\text { Proses pemasukan } \\
\text { data berhasil, klik } \\
\text { simpan, data } \\
\text { tersimpan di } \\
\text { database }\end{array}$ \\
\hline Pengamatan & $\begin{array}{l}\text { Data berhasil } \\
\text { tersimpan dalam } \\
\text { database }\end{array}$ \\
\hline Kesimpulan & Sukses \\
\hline \multicolumn{2}{|c|}{ Ubah Data } \\
\hline Data Masukan & $\begin{array}{l}\text { Mengubah atribut } \\
\text { data biodata calon } \\
\text { siswa yang sudah } \\
\text { ada dalam database }\end{array}$ \\
\hline $\begin{array}{l}\text { Yang } \\
\text { diharapkan }\end{array}$ & $\begin{array}{l}\text { Proses masukan data } \\
\text { benar, klik ubah dan } \\
\text { data yang sudah } \\
\text { diubah masuk } \\
\text { kedalam database }\end{array}$ \\
\hline Pengamatan & $\begin{array}{l}\text { Data berhasil diubah } \\
\text { dan tersimpan dalam } \\
\text { database }\end{array}$ \\
\hline Kesimpulan & Sukses \\
\hline \multicolumn{2}{|c|}{ Hapus Data } \\
\hline Data Masukan & $\begin{array}{l}\text { Menghapus atribut } \\
\text { data biodata calon } \\
\text { siswa yang sudah } \\
\text { ada dalam database }\end{array}$ \\
\hline $\begin{array}{l}\text { Yang } \\
\text { diharapkan }\end{array}$ & $\begin{array}{l}\text { Klik hapus dan data } \\
\text { terhapus dalam } \\
\text { database }\end{array}$ \\
\hline Pengamatan & $\begin{array}{l}\text { Data berhasil } \\
\text { dihapus dalam } \\
\text { database }\end{array}$ \\
\hline Kesimpulan & Sukses \\
\hline \multicolumn{2}{|c|}{ Cetak Data } \\
\hline Data Masukan & $\begin{array}{l}\text { Mencetak data } \\
\text { biodata calon siswa } \\
\text { yang sudah ada } \\
\text { dalam database }\end{array}$ \\
\hline Yang & Klik cetak, pilih data \\
\hline
\end{tabular}




\begin{tabular}{|l|l|}
\hline diharapkan & yang akan dicetak \\
\hline Pengamatan & Data berhasil dicetak \\
\hline Kesimpulan & Sukses \\
\hline \multicolumn{2}{|c|}{ Cari Data } \\
\hline Data Masukan & $\begin{array}{l}\text { Mengisi atribut data } \\
\text { biodata calon siswa } \\
\text { yang akan dicari } \\
\text { dengan benar }\end{array}$ \\
\hline $\begin{array}{l}\text { Yang } \\
\text { diharapkan }\end{array}$ & $\begin{array}{l}\text { Proses pencarian } \\
\text { data berhasil }\end{array}$ \\
\hline Pengamatan & $\begin{array}{l}\text { Data berhasil dicari } \\
\text { dalam database }\end{array}$ \\
\hline Kesimpulan & Sukses \\
\hline
\end{tabular}

3. Data Bukti Pendaftaran

Tabel 4 Pengujian Form Data Bukti Pendaftaran

\begin{tabular}{|l|l|}
\hline \multicolumn{2}{|c|}{ Kasus dan Hasil Uji } \\
\hline Simpan Data \\
\hline Data Masukan & $\begin{array}{l}\text { Mengisi atribut data } \\
\text { bukti pendaftaran } \\
\text { yang telah } \\
\text { disediakan dengan } \\
\text { benar }\end{array}$ \\
\hline $\begin{array}{l}\text { Yang } \\
\text { diharapkan }\end{array}$ & $\begin{array}{l}\text { Proses pemasukan } \\
\text { data berhasil, klik } \\
\text { simpan, data yang } \\
\text { tersimpan dalam } \\
\text { database }\end{array}$ \\
\hline Pengamatan & $\begin{array}{l}\text { Data berhasil } \\
\text { tersimpan dalam } \\
\text { database }\end{array}$ \\
\hline Kesimpulan & Sukses \\
\hline \multicolumn{2}{|c|}{ Cetak Data } \\
\hline Data Masukan & $\begin{array}{l}\text { Mencetak data bukti } \\
\text { pendaftaran yang } \\
\text { sudah ada dalam } \\
\text { database }\end{array}$ \\
\hline $\begin{array}{l}\text { Yang } \\
\text { diharapkan }\end{array}$ & $\begin{array}{l}\text { Klik cetak, pilih data } \\
\text { yang akan dicetak }\end{array}$ \\
\hline Pengamatan & Data berhasil dicetak \\
\hline Kesimpulan & Sukses \\
\hline
\end{tabular}

\section{Data Bukti Pembayaran Registrasi Siswa Baru}

Tabel 5 Pengujian Form Data Bukti Pembayaran Registrasi Siswa Baru

\begin{tabular}{|l|l|}
\hline \multicolumn{2}{|c|}{ Kasus dan Hasil Uji } \\
\hline Simpan Data \\
\hline Mata & $\begin{array}{l}\text { Mengisi atribut data } \\
\text { bukti pembayaran } \\
\text { registrasi siswa baru } \\
\text { yang telah } \\
\text { disediakan dengan } \\
\text { benar }\end{array}$ \\
\hline $\begin{array}{l}\text { Yang } \\
\text { diharapkan }\end{array}$ & $\begin{array}{l}\text { Proses pemasukan } \\
\text { data berhasil, klik } \\
\text { simpan, data yang } \\
\text { tersimpan dalam } \\
\text { database }\end{array}$ \\
\hline Pengamatan & $\begin{array}{l}\text { Data berhasil } \\
\text { tersimpan dalam } \\
\text { database }\end{array}$ \\
\hline \multicolumn{2}{|c|}{ Cetak Data } \\
\hline Kesimpulan & $\begin{array}{l}\text { Mencetak data bukti } \\
\text { pembayaran } \\
\text { registrasi siswa baru } \\
\text { yang sudah ada } \\
\text { dalam database }\end{array}$ \\
\hline Data Masukan \\
\hline $\begin{array}{l}\text { Yang } \\
\text { diharapkan }\end{array}$ & $\begin{array}{l}\text { Klik cetak, pilih data } \\
\text { yang akan dicetak }\end{array}$ \\
\hline Pengamatan & Data berhasil dicetak \\
\hline Kesimpulan & Sukses \\
\hline
\end{tabular}

\section{Data Bukti Kembali Berkas}

Tabel 6 Pengujian Form Data Bukti Kembali Berkas

\begin{tabular}{|l|l|}
\hline \multicolumn{2}{|c|}{ Kasus dan Hasil Uji } \\
\hline Simpan Data \\
\hline Mata & $\begin{array}{l}\text { Mengisi atribut data } \\
\text { bukti kembali berkas } \\
\text { yang telah } \\
\text { disediakan dengan } \\
\text { benar }\end{array}$ \\
\hline $\begin{array}{l}\text { Yang } \\
\text { diharapkan }\end{array}$ & $\begin{array}{l}\text { Proses pemasukan } \\
\text { data berhasil, klik } \\
\text { simpan, data yang } \\
\text { tersimpan dalam } \\
\text { database }\end{array}$ \\
\hline Pengamatan & $\begin{array}{l}\text { Data berhasil } \\
\text { tersimpan dalam } \\
\text { database }\end{array}$ \\
\hline \multicolumn{2}{|c|}{ Cetak Data } \\
\hline Kesimpulan & $\begin{array}{l}\text { Mencetak data bukti } \\
\text { kembali berkas yang }\end{array}$ \\
\hline
\end{tabular}




\begin{tabular}{|l|l|}
\hline & $\begin{array}{l}\text { sudah ada dalam } \\
\text { database }\end{array}$ \\
\hline $\begin{array}{l}\text { Yang } \\
\text { diharapkan }\end{array}$ & $\begin{array}{l}\text { Klik cetak, pilih data } \\
\text { yang akan dicetak }\end{array}$ \\
\hline Pengamatan & Data berhasil dicetak \\
\hline Kesimpulan & Sukses \\
\hline
\end{tabular}

6. Data Nilai Hasil Tes Calon Siswa

Tabel 7 Pengujian Form Data Nilai Hasil Tes Calon Siswa

\begin{tabular}{|c|c|}
\hline \multicolumn{2}{|c|}{ Kasus dan Hasil Uji } \\
\hline \multicolumn{2}{|c|}{ Simpan Data } \\
\hline Data Masukan & $\begin{array}{l}\text { Mengisi atribut data } \\
\text { nilai hasil tes calon } \\
\text { siswa yang telah } \\
\text { disediakan dengan } \\
\text { benar }\end{array}$ \\
\hline $\begin{array}{l}\text { Yang } \\
\text { diharapkan }\end{array}$ & $\begin{array}{l}\text { Proses pemasukan } \\
\text { data berhasil, klik } \\
\text { simpan, data } \\
\text { tersimpan di } \\
\text { database }\end{array}$ \\
\hline Pengamatan & $\begin{array}{l}\text { Data berhasil } \\
\text { tersimpan dalam } \\
\text { database }\end{array}$ \\
\hline Kesimpulan & Sukses \\
\hline \multicolumn{2}{|c|}{ Ubah Data } \\
\hline Data Masukan & $\begin{array}{l}\text { Mengubah atribut } \\
\text { data nilai hasil tes } \\
\text { calon siswa yang } \\
\text { sudah ada dalam } \\
\text { database }\end{array}$ \\
\hline $\begin{array}{l}\text { Yang } \\
\text { diharapkan }\end{array}$ & $\begin{array}{l}\text { Proses masukan data } \\
\text { benar, klik ubah dan } \\
\text { data yang sudah } \\
\text { diubah masuk } \\
\text { kedalam database }\end{array}$ \\
\hline Pengamatan & $\begin{array}{l}\text { Data berhasil diubah } \\
\text { dan tersimpan dalam } \\
\text { database }\end{array}$ \\
\hline Kesimpulan & Sukses \\
\hline \multicolumn{2}{|c|}{ Hapus Data } \\
\hline Data Masukan & $\begin{array}{l}\text { Menghapus atribut } \\
\text { data nilai hasil tes } \\
\text { calon siswa yang } \\
\text { sudah ada dalam } \\
\text { database }\end{array}$ \\
\hline $\begin{array}{l}\text { Yang } \\
\text { diharapkan }\end{array}$ & $\begin{array}{l}\text { Klik hapus dan data } \\
\text { terhapus dalam } \\
\text { database }\end{array}$ \\
\hline
\end{tabular}

\begin{tabular}{|l|l|}
\hline Pengamatan & $\begin{array}{l}\text { Data berhasil } \\
\text { dihapus dalam } \\
\text { database }\end{array}$ \\
\hline Kesimpulan & Sukses \\
\hline \multicolumn{2}{|c|}{ Cetak Data } \\
\hline Data Masukan & $\begin{array}{l}\text { Mencetak data nilai } \\
\text { hasil tes calon siswa } \\
\text { yang sudah ada } \\
\text { dalam database }\end{array}$ \\
\hline $\begin{array}{l}\text { Yang } \\
\text { diharapkan }\end{array}$ & $\begin{array}{l}\text { Klik cetak, pilih data } \\
\text { yang akan dicetak }\end{array}$ \\
\hline Pengamatan & Data berhasil dicetak \\
\hline Kesimpulan & Sukses \\
\hline \multicolumn{2}{|c|}{ Cari Data } \\
\hline Data Masukan & $\begin{array}{l}\text { Mengisi atribut data } \\
\text { nilai hasil tes calon } \\
\text { siswa yang akan } \\
\text { dicari dengan benar }\end{array}$ \\
\hline $\begin{array}{l}\text { Yang } \\
\text { diharapkan }\end{array}$ & $\begin{array}{l}\text { Proses pencarian } \\
\text { data berhasil }\end{array}$ \\
\hline Pengamatan & $\begin{array}{l}\text { Data berhasil dicari } \\
\text { dalam database }\end{array}$ \\
\hline Kesimpulan & Sukses \\
\hline
\end{tabular}

\section{Pengolahan Cetak Laporan}

Tabel 8 Pengujian Pengolahan Cetak Laporan

\begin{tabular}{|l|l|}
\hline \multicolumn{2}{|c|}{ Kasus dan Hasil Uji } \\
\hline Cetak Laporan Biodata Calon Siswa \\
\hline Data Masukan & $\begin{array}{l}\text { Data Biodata Calon } \\
\text { Siswa }\end{array}$ \\
\hline $\begin{array}{l}\text { Yang } \\
\text { diharapkan }\end{array}$ & $\begin{array}{l}\text { Proses pencetakan } \\
\text { data berhasil }\end{array}$ \\
\hline Pengamatan & $\begin{array}{l}\text { Data berhasil dicetak } \\
\text { dari dalam database }\end{array}$ \\
\hline Kesimpulan & Sukses \\
\hline $\begin{array}{l}\text { Cetak Laporan Bukti Pendaftaran } \\
\text { Penerimaan Siswa Baru }\end{array}$ \\
\hline Data Masukan & $\begin{array}{l}\text { Data Bukti } \\
\text { Pendaftaran } \\
\text { Penerimaan Siswa } \\
\text { Baru }\end{array}$ \\
\hline $\begin{array}{l}\text { Yang } \\
\text { diharapkan }\end{array}$ & $\begin{array}{l}\text { Proses pencetakan } \\
\text { data berhasil }\end{array}$ \\
\hline Pengamatan & $\begin{array}{l}\text { Data berhasil dicetak } \\
\text { dari dalam database }\end{array}$ \\
\hline Kesimpulan & Sukses \\
\hline $\begin{array}{l}\text { Cetak Laporan Bukti Pembayaran } \\
\text { Registrasi Siswa Baru }\end{array}$ \\
\hline
\end{tabular}




\begin{tabular}{|l|l|}
\hline Data Masukan & $\begin{array}{l}\text { Data Bukti } \\
\text { Pembayaran } \\
\text { Registrasi Siswa } \\
\text { Baru }\end{array}$ \\
\hline $\begin{array}{l}\text { Yang } \\
\text { diharapkan }\end{array}$ & $\begin{array}{l}\text { Proses pencetakan } \\
\text { data berhasil }\end{array}$ \\
\hline Pengamatan & $\begin{array}{l}\text { Data berhasil dicetak } \\
\text { dari dalam database }\end{array}$ \\
\hline Kesimpulan & Sukses \\
\hline $\begin{array}{l}\text { Cetak Laporan Bukti Kembali } \\
\text { Berkas Siswa Baru }\end{array}$ \\
\hline Data Masukan & $\begin{array}{l}\text { Data Bukti Kembali } \\
\text { Berkas Siswa Baru }\end{array}$ \\
\hline $\begin{array}{l}\text { Yang } \\
\text { diharapkan }\end{array}$ & $\begin{array}{l}\text { Proses pencetakan } \\
\text { data berhasil }\end{array}$ \\
\hline Pengamatan & $\begin{array}{l}\text { Data berhasil dicetak } \\
\text { dari dalam database }\end{array}$ \\
\hline Kesimpulan & Sukses \\
\hline $\begin{array}{l}\text { Cetak Laporan Nilai Hasil Tes Calon } \\
\text { Siswa }\end{array}$ & $\begin{array}{l}\text { Data Nilai Hasil Tes } \\
\text { Calon Siswa }\end{array}$ \\
\hline Data Masukan & $\begin{array}{l}\text { Proses pencetakan } \\
\text { data nilai hasil tes } \\
\text { calon siswa }\end{array}$ \\
\hline $\begin{array}{l}\text { Yang } \\
\text { diharapkan }\end{array}$ & $\begin{array}{l}\text { Data berhasil dicetak } \\
\text { dari dalam database }\end{array}$ \\
\hline Pengamatan & Sukses \\
\hline Kesimpulan &
\end{tabular}

Pengujian sistem dilakukan untuk menguji sistem baru terbebas dari kesalahan-kesalahan. Pengujian dilakukan dengan metode blackbox yang berfokus pada persyaratan fungsional dari sistem yang dibangun.

\section{KESIMPULAN}

Dari hasil penelitian yang telah dipaparkan pada bagian sebelumnya, maka dapat disimpulkan bahwa dengan adanya sistem informasi penerimaan siswa baru ini dapat membantu pihak sekolah dalam pengelolaan data-data calon siswa secara terkomputerisasi serta dengan adanya fitur laporan pada sistem informasi ini dapat mempercepat pihak sekolah dalam proses pencetakan laporan-laporan jika sewaktu-waktu dibutukan. Adapun saran yang ingin disampaikan pada penelitian ini adalah
Sebaiknya diberikan fiture backup database untuk menghindari kerusakan data sewaktu-waktu., Sebaiknya ditambahkan tingkatan hak akses pada saat login sistem. Sistem ini masih bersifat desktop sehingga diharapkan pada penelitian selanjutnya dapat menggunakan online.

\section{REFERENSI}

[1] Arief, M. (2011). Pemrograman Web Dinamis Menggunakan Php dan Mysql. ANDI: Yogyakarta.

[2] Arief, M. R. (2011). Pemrograman Web Dinamis menggunakan PHP dan MySQL. Yogyakarta: Andi Publisher.

[3] Hakim, Lukmanul, 2008, Membongkar Trik Rahasia para master PHP, Yogyakarta : Penerbit Lokomedia.

[4] Jogiyanto, H. (2005). Analisis \& Desain Sistem Informasi Pendekatan Terstruktur Teori dan Praktek Aplikasi Bisnis. Yogya: ANDI.

[5] Nugroho, B. (2015). Database Relational dengan MySQL. Yogyakarta: Andi.

[6] Wahana Komputer, 2007 : Konsep Sistem Basis Data dan Implementasinya, Yogjakarta : Graha Ilmu 